\title{
Pengembangan Media Pembelajaran E-Comic Berbasis Problem Based Learning Materi Siklus Air pada Muatan IPA
}

\author{
Ni Luh Putu Ari Laksmi ${ }^{1 *}$, Ni Wayan Suniasih ${ }^{2}$ iD \\ 1,2 Jurusan Pendidikan Dasar, Universitas Pendidikan Ganesha, SIngaraja, Indonesia \\ *Corresponding author: niluhputuarilaksmi02@undiksha.ac.id
}

\begin{abstract}
Abstrak
Penelitian ini dilatarbelakangi dengan kurangnya penggunaan media pembelajaran yang bervariasi dalam situasi pandemic Covid-19. Penelitian ini bertujuan untuk mendeskripsikan rancang bangun dan mengetahui validitas media E-Comic berbasis Problem Based Learning pada materi siklus air kelas V SD. Penelitian ini merupakan jenis penelitian pengembangan dengan menggunakan model pengembangan ADDIE dengan lima tahap yaitu Analyze, Design, Development, Implementation, dan Evaluation. Subjek uji coba yang digunakan dalam penelitian ini yaitu ahli isi pembelajaran, ahli desain pembelajaran, ahli media pembelajaran dan tiga orang siswa kelas V SD. Instrumen yang digunakan dalam pengumpulan data yaitu angket. Data penelitian dianalisis dengan menggunakan analisis deskriptif kuantitatif dan analisis deskriptif kualitatif. Hasil pengembangan media E-Comic berbasis Problem Based Learning layak dikembangkan berdasarkan hasil validasi dari para ahli. Hasil penilaian validator dari ahli isi pembelajaran diperoleh $97 \%$ dengan kategori sangat baik, ahli desain pembelajaran diperoleh $97 \%$ dengan kategori sangat baik, ahli media pembelajaran $100 \%$ kategori sangat baik dan subjek uji perorangan diperoleh $90 \%$ dengan kategori sangat baik. Hasil keseluruhan dari para ahli dan uji coba perorangan terkualifikasi sangat baik. Media E-Comic berbasis Problem Based Learning layak digunakan dengan pembelajaran siklus air pada muatan IPA kelas V SD.
\end{abstract}

Kata kunci: Media E-Comic, Problem Based Learning, Siklus Air

\section{Abstract}

This research is motivatied by the lack of use of various learning media in the Covid-19 pandemic situation. This study aimed to describe the design and determine the validity of E-Comic media based on Problem Based Learning on the water cycle material on fifth-grade in elementary school. This research is a type of development research using a development model, ADDIE with five stages namely Analyze, Design, Development, Implementation, and Evaluation. The trial subjects used in this study were content experts, instructional design experts, instructional media experts, dan three grade V SD students. The instrument used in data collection was a questionnaire. The research data were analyzed using quantitative descriptive analysis and qualitative descriptive analysis. The results of the development of E-Comic media based on Problem Based Learning are feasible to be developed based on the results of validation from experts. The results of the validator's assessment of the learning content expert were obtained $97 \%$ in the very good category, the learning design expert was obtained $97 \%$ in the very good category, the learning media expert was $100 \%$ in the very good category and the individual test subjects were obtained $90 \%$ with the very good category. The overall results from the qualified experts and individual trials were excellent. E-Comic media based on Problem Based Learning is feasible to use water cycle learning media in the fifth-grade science content of SD.

Keywords: E-Comic Media, Problem Based Learning, Water Cycle
History:
Received : 7 Januari 2021
Revised : 3 Februari 2021
Accepted : 2 Maret 2021
Published : 25 Maret 2021

Publisher: Undiksha Press

Licensed: This work is licensed under

a Creative Commons Attribution 4.0 License

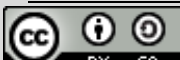

\section{Pendahuluan}

Pembelajaran IPA merupakan salah satu materi pembelajaran yang wajib dipelajari dalam pendidikan sekolah dasar (Widiana, 2016). Proses pembelajaran IPA di 
sekolah dasar tidak hanya berfokus pada pengetahuan pemahaman tetapi juga pengembangan keterampilan berpikir kritis (Zainudin \& Wijayanti, 2021). Pembelajaran IPA merupakan proses belajar menjadi menyenangkan dan dapat meningkatkan kemampuan berpikir kritis siswa dalam mengembangkan pengetahuan dan pemahaman tentang lingkungan sekitarnya (Rubini, B., Permanasari, A., \& Yuningsih, 2018; Saripudin, E., Sari, IJ, \& Mukhtar, 2018). Pembelajaran IPA harus dikembangkan agar berpusat pada siswa, artinya melibatkan keaktifan siswa dalam proses pembelajaran untuk mengeksplorasi kemampuan siswa, meningkatkan kemampuan pemecahan masalah dan meningkatkan rasa ingin tahu dalam setiap belajar (Astuti \& Setiawan, 2013; Dewi et al., 2013). Hal tersebut akan tercapai dengan baik apabila proses pembelajaran IPA di sekolah dasar menggunakan berbagai komponen pembelajaran yaitu salah satunya media pembelajaran. Beberapa upaya telah dilakukan untuk mengoptimalkan pembelajaran IPA di sekolah dasar, proses pembelajaran agar melibatkan keaktifan siswa membutuhkan media pembelajaran sesuai dengan karakteristik siswa untuk meningkatkan hasil belajar siswa dan motivasi belajar (Pratama et al., 2019; Wahyugi \& Fatmariza, 2021). Selain itu media pembelajaran juga harus dikembangkan dengan berbagai inovasi mengikuti perkembangan teknologi (Manuaba, 2017; Putri, 2017).

Kenyataan yang terjadi di lapangan, aktivitas pembelajaran yang dilakukan oleh guru belum sesuai dengan apa yang diharapkan (Aprilla, 2020). Media pembelajaran yang digunakan hanya terpaku pada satu sumber buku ajar, sehingga siswa kesulitan dalam memahami materi karena pemahaman akan objek dalam materi tidak semuanya jelas (Januarisman \& Ghufron, 2016; Nurhasanah, I. A., Sujana, A., \& Sudin, 2016). Pengunaan media pembelajaran di sekolah dasar mempunyai peran penting yang harus mendapat perhatian guru, karena siswa pada tingkat sekolah dasar memiliki kemampuan yang terbatas dalam memahami materi yang bersifat abstrak (Musafanah, 2017). Ketepatan penggunaan media pembelajaran tidak terlepas dari pemahaman terhadap ragam dan karakteristik media tersebut (Rohmanurmeta, 2019a). Penggunaan media pengajaran dapat membantu pencapaian keberhasilan belajar (Putri, 2017; Widiyatmoko, 2014). Media berperan sangat penting sebagai pembawa informasi dari guru kepada siswa (Yudasmara, Namun, guru perlu mempertimbangkan tingkat kemenarikan penggunaan dari media pembelajaran (Lailiyah, 2020). Pemilihan media pembelajaran harusnya sesuai dengan kebutuhan siswa.

Hal ini didukung hasil wawancara dengan guru wali kelas V SD Negeri 15 Dauh Puri bahwa guru belum menggunakan media pembelajaran khusus yang berbasis elektronik dalam menyampaikan materi pembelajaran. Guru menggunakan buku siswa sebagai sumber belajar. Hasil observasi menunjukkan bahwa siswa lebih senang belajar menggunakan media gambar serta warna yang menarik, apalagi dalam belajar IPA siswa lebih tertarik dengan materi yang menyajikan gambar-gambar yang jelas. Anak sekolah dasar mempunyai karakteristik yaitu berpikir naratif, dan memiliki rasa ingin tahu yang tinggi (Pratiwi, 2017). Proses pembelajaran kurang efektif dan tidak mengaktifkan siswa, hal ini membuat siswa sulit untuk memahami materi dan cenderung akan bosan dalam belajar kegiatan (Rostikawati \& Permanasari, 2016).

Jika permasalahan tersebut terus berlanjut maka perlu dibuat suatu alternatif solusi yang dianggap efektif dan inovatif dalam mengatasi keterbatasan tersebut dalam proses pembelajaran. Mengatasi rasa bosan dan jenuh siswa dalam proses pembelajaran, guru sebaiknya menggunakan media pembelajaran atau model pembelajaran agar proses pembelajaran berjalan dengan efektif (Utami, 2019). Pembelajaran yang membuat siswa menjadi aktif sangat mendukung untuk meningkatkan kemampuan berpikir dan komunikasi terstruktur. Penggunaan kartun atau komik dalam pembelajaran juga mulai mendapatkan perhatian diantara pendidik karena dapat meningkatkan pemahaman dan ketertarikkan, meningkatkan motivasi untuk belajar, memperbaiki perilaku, meningkatkan produktivitas 
dan kreativitas, mengurangi stress dan kegelisahan, meningkatkan keaktifan partisipasi siswa dalam proses pembelajaran, dan dapat mengurangi kebosanan (Aiman, 2020). Seiring dengan perkembangan teknologi komik pun sekarang sudah ada berbentuk elektronik. E-Comic atau biasanya disebut komik elektronik merupakan komik digital yang digunakan dalam menyalurkan pesan dalam bidang ilmu pengetahuan, yang mempunyai tampilan menarik atau unik dan bersifat hiburan (Rivai, 2021).

Temuan penelitian memproleh hasil bahwa penggunaan media pembelajaran EComic mampu memotivasi belajar anak (Indriasih et al., 2020a). Media pembelajaran ecomic layak diterapkan dalam pembelajaran untuk meningkatkan kecakapan hidup anak usia dini (Indriasih et al., 2020b). Dengan demikian E-Comic dapat mempermudah siswa untuk mengakses materi pembelajaran pada masa pandemi Covid-19. Berdasarkan pemaparan masalah tersebut sangat penting dikembangkan media pembelajaran E-Comic berbasis Problem Based Learning pada materi siklus air kelas V SD dengan ini diharapkan dapat meningkatkan minat membaca siswa dan cara berpikir kritis siswa terhadap keterampilan pemecahan masalah. Adapun tujuan penelitian pengembangan media E-Comic ini yaitu untuk mendeskripsikan rancang bangun media pembelajaran E-Comic berbasis Problem Based Leaning materi Siklus Air, dan untuk mendeskripsikan kelayakan media E-Comic berbasis Problem Based Leaning dalam pembelajaran.

\section{Metode}

Penelitian ini adalah jenis penelitian dan pengembangan (Research and Development) yang menggunakan model ADDIE. Model ADDIE terdiri atas lima langkah, yaitu: (1) analisis (analyze), (2) perancangan (design), (3) pengembangan (development), (4) implementasi (implementation), dan (5) evaluasi (evaluation) (Tegeh, 2014). Pengembangan media E-Comic melalui tahap tersebut dan melalui kegiatan uji coba produk yaitu uji para ahli dan uji perorangan. Adapun subjek uji penelitian ini adalah ahli isi pembelajaran, ahli desain pembelajaran, ahli media pembelajaran dan tiga orang siswa kelas V SD Negeri 15 Dauh Puri dengan prestasi belajar yang berbeda-beda untuk uji coba. Metode pengumpulan data yang digunakan adalah metode nontes berupa kuesioner. Kuesioner diberikan kepada validator dan subjek uji coba perorangan, untuk mengetahui kelayakan media E-Comic dari ahli isi pembelajaran, ahli desain pembelajaran, dan ahli media pembelajaran, sedangkan uji coba perorangan dilakukan untuk mengetahui kemenarikan media pembelajaran E-Comic berbasis Problem Based Learning .

Teknik analisis data yang digunakan yaitu analisis deskriptif kuantitatif dan analisis deskriptif kualitatif. Analisis deskriptif kuantitatif digunakan dalam mengelola data hasil validasi para ahli dan kuesioner respon subjek uji coba perorangan dalam bentuk deskriptif persentase. Untuk memberikan makna dan pengambilan keputusan dengan mengunakan ketetapan teknik analisis deskriptif kualitatif digunakan sebagai berikut.

Tabel 1. Konversi Tingkat Pencapaian dengan Skala 5

\begin{tabular}{ccc}
\hline Tingkat Pencapaian $(\%)$ & Kualifikasi & Keterangan \\
\hline $90-100$ & Sangat baik & Tidak perlu direvisi \\
$75-89$ & Baik & Sedikit direvisi \\
$65-79$ & Cukup & Direvisi secukupnya \\
$55-64$ & Kurang & Banyak hal yang direvisi \\
$1-54$ & Sangat kurang & Diulangi membuat produk \\
\hline
\end{tabular}

(Sumber: Tegeh, dkk 2010:83) 


\section{Hasil dan Pembahasan Hasil}

Tahapan analisis terdiri dari analisis kebutuhan, analisis kurikulum, analisis karakteristik siswa, dan analisis kriteria media pembelajaran yang baik. Sebuah analisis dilakukan dengan wawancara guru wali kelas V SD Negeri 15 Dauh Puri untuk menentukan kebutuhan yang diperlukan dalam proses pembelajaran, terutama dalam pembelajaran IPA. Hasil analisis kebutuhan menyatakan bahwa guru selalu menggunakan buku untuk kegiatan pembelajaran online. Kelengkapan materi konten IPA di buku siswa tidak lengkap, guru tidak pernah menggunakan media pembelajaran selama pembelajaran online. Oleh karena itu, pengembangan media pembelajaran e-comic berbasis problem based learning materi siklus air pada muatan ipa. Analisis kurikulum dilakukan dengan menganalisis kompetensi inti, kompetensi dasar, dan menentukan indikator pencapaian kompetensi pada materi siklus air.

Analisis karakteristik siswa dilakukan untuk menganalisis tingkat perkembangan kognitif menggunakan e-comic berbasis problem-based learning. Analisis karakteristik siswa menunjukkan bahwa siswa sekolah dasar lebih suka menggunakan benda-benda konkret dengan menampilkan gambar yang menarik, menonton video, dan mendengarkan audio. Siswa akan dalam proses pembelajaran akan lebih menyenangkan. Analisis ecomic yang digunakan untuk menganalisis kriteria e-comic yang baik, sehingga sangat cocok untuk anak-anak sekolah dasar. E-comic materi siklus air yang dikembangkan dipandu oleh 7 aspek, yaitu: (a) organisasi, (b) daya tarik, (c) huruf dan gambar, (d) instruksi mandiri, (e) mandiri, (f) adaptif, dan (g) penggunaan (Purnomo, H., \& Wilujeng, 2016).

Setelah tahap analisis, kemudian dilanjutkan dengan tahap desain, yang dilakukan dengan merancang e-comic. Tahap ini dimulai dengan menentukan bahan yang terkandung dalam materi siklus air E-comic adalah de veloped menggunakan software Canva pada kertas A4 berukuran $21 \mathrm{~cm}$ x 29,7 cm. Desain e-comic berkonsultasi dengan dosen pembimbing untuk mendapatkan masukan dan saran untuk perbaikan. Setelah disetujui oleh pengawas, selanjutnya dilanjutkan ke tahap pengembangan. Tahap pengembangan dilakukan dengan mengembangkan e-comic materi siklus air yang disesuaikan dengan desain. E-comic dikembangkan dengan sampul, kata pengantar, daftar isi, kompetensi dasar, indicator pencapaian, tujuan pembelajaran, petunjuk, isi/materi dengan gambar yang menarik, audio, video, ringkasan, dan latihan. Setelah e-comic telah dikembangkan, langkah berikutnya adalah untuk melaksanakan uji coba.

Produk dari penelitian ini berupa media pembelajaran, yaitu media E-Comic berbasis Problem Based Learning materi siklus air kelas V SD. Hasil validitas pengembangan media E-Comic berbasis Problem Based Learning pada ahli isi pembelajaran dengan presentase sebesar $97 \%$ berada pada kualifikasi sangat baik, ahli isi desain pembelajaran dengan presentase sebesar $97 \%$ berada pada kualifikasi sangat baik, dari ahli media pembelajaran dengan presentase sebesar $100 \%$ berada pada kualifikasi sangat baik. Berdasarkan penilaian dari validator dan uji perorangan bahwa media E-Comic berbasis Problem Based Learning tidak perlu direvisi. Validator juga memberikan komentar dan saran untuk menyempurnakan media E-Comic berbasis Problem Based Learning berikut komentar dan saran para ahli dan uji perorangan disajikan pada Tabel 2.

Tabel 2. Komentar dan saran para ahli dan uji perorangan

\begin{tabular}{rlll}
\hline No. & Subjek uji coba & Komentar dan Saran & Revisi \\
\hline 1. & Uji ahli isi & - & - \\
pembelajaran & & Memperjelas petunjuk soal \\
2. & $\begin{array}{l}\text { Uji ahli desain } \\
\text { pembelajaran }\end{array}$ & Petunjuk soal diperjelas & \\
\hline
\end{tabular}




\begin{tabular}{clll}
\hline No. & Subjek uji coba & Komentar dan Saran & Revisi \\
\hline 3. $\begin{array}{l}\text { Uji ahli media } \\
\text { pembelajaran }\end{array}$ & $\begin{array}{l}\text { Petunjuk setelah cover } \\
\text { digabung, dan Teks pada } \\
\text { cover diperjelas. }\end{array}$ & $\begin{array}{l}\text { Menggabungkan petujuk pada } \\
\text { dan E-Comic setelah cover, } \\
\text { memperjelas teks pada cover }\end{array}$ \\
4. Uji perorangan & $\begin{array}{l}\text { Penampilan E-Comic sangat } \\
\text { menarik, tulisan dapat dibaca } \\
\text { dengan jelas, dan materi yang } \\
\text { disampaikan dapat dipahami } \\
\text { dengan baik, bagus dan dapat } \\
\text { membantu mengerti materi, } \\
\text { dan gambarnya bagus sekali }\end{array}$ \\
\hline
\end{tabular}

Berdasarkan komentar dan saran subjek uji coba berikut tampilan atau visualisasi revisi dari ahli media pembelajaran. Hasil Review media E-Comic berbasis Problem Based Learning dari hasil isi pembelajaran yaitu materi IPA tersebar pada skor 4 (sangat baik) dan 3 (baik). Kualitas aspek materi mendapat kriteria sangat baik dengan presentasi $97 \%$ dari ahli isi pembelajaran yang kriteria penilain meliputi: (a) materi, (b) kebahasaan, (c) evaluasi. Hasil Review dari ahli desain pembelajaran terdapat komponen materi pembelajaran tersebar pada skor 4 (sangat baik), 3 (baik). Dari hasil sebaran skor tersebut didapatkan hasil presentase sebesar 97\% dengan kriteria sangat baik. Adapun kriteria aspek penilaian desaian pembelajaran meliputi: (a) tujuan, (b) strategi, (c) evaluasi.

Hasil Review ahli media pembelajaran terhadap komponen materi pembelajaran tersebar pada skor 4 (sangat baik), 3 (baik). Dari hasil sebaran skor tersebut didapatkan hasil akhir dengan persentase $100 \%$ kriteria sangat baik. Adapun aspek kriteria penilaian media pembelajaran meliputi: (a) desain pesan, (b) teknik, (c) pembaharuan media. Hasil Review media pembelajaran E-Comic berbasis Problem Based Learning dilihat dari uji coba perorangan media ini mendapatkan persentase sebesar $90 \%$ dengan kriteria yang sangat baik. Dilihat dari komentar yang diberikan oleh subjek uji coba perorangan media pembelajaran $E$ Comic berbasis Problem Based Learning mendapat respon positif dari siswa. Hasil akhir dari pengembangan media pembelajaran E-Comic berbasis Problem Based Learning dapat dilihat pada gambar berikut.

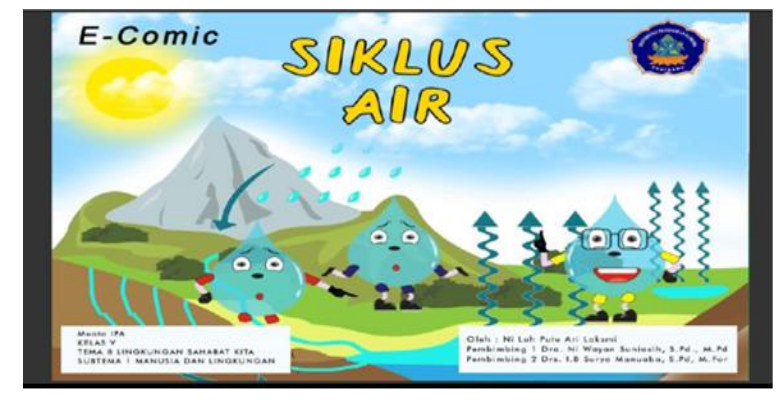

Gambar 1. Tampilan Cover Media E-Comic

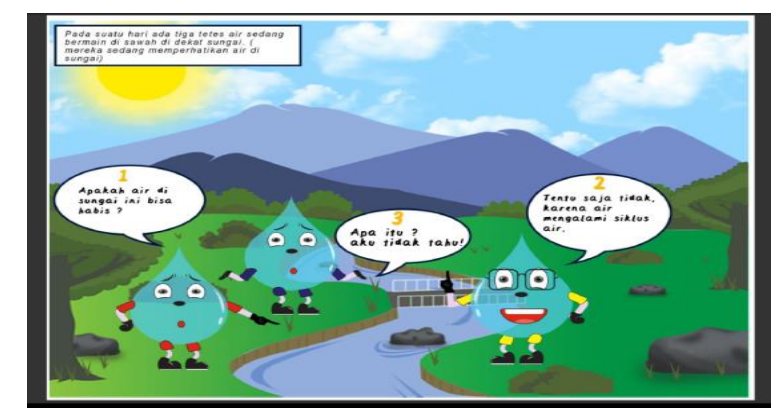

Gambar 2. Tampilan Isi Media E-Comic

\section{Pembahasan}

Media pembelajaran E-Comic berbasis Problem Based Learning yang dikembangkan itu dikatakan sangat baik karena memenuhi semua aspek . Dari segi materi, terlihat bahwa ecomic berbasis Problem Based Learning yang dikembangkan mengandung aspek kemandirian. Aspek mandiri menunjukkan bahwa siswa mempelajari materi secara menyeluruh karena materi sesuai dengan kompetensi dasar. Media yang dikembangkan 
memuat materi tematik yaitu pada muatan IPA khususnya materi siklus air. Media disertai dengan gambar-gambar ilustrasi pendukung yang sesuai dengan materi, dan disertai cerita berupa penjelasan materi, sehingga siswa mudah dalam memahami materi saat membaca maupun mengamati materi. Dalammemperjelas isi pada tulisan, ilustrasi berguna sebagai pendukung uraian yang memberikan gambaran konkret dan jelas (Mahuze, 2017).

Media pembelajaran e-comic berbasis Problem Based Learning siswa belajar secara aktif dan mandiri karena tujuan pembelajaran dalam e-comic mengikuti kompetensi yang dicapai. Materi dilengkapi dengan gambar, video, dan audio yang relevan dengan materi dan karakteristik peserta didik. Anak-anak SD usia sekolah dasar memecahkan masalah dan berpikir secara sistematis tentang objek konkrit dan contoh sehingga anak-anak dapat memecahkan masalah dalam kehidupan sehari-hari. Oleh karena itu, peserta didik sekolah dasar dapat difasilitasi oleh e-comic berbasis problem-based learning yang telah dikembangkan. E-comic berbasis problem based learning pada materi siklus air dapat membuat siswa berinteraksi secara langsung, seperti aktif mengamati gambar, aktif membaca materi, mengamati warna atau bmenulis, mendengarkan suara, animasi, dan bahkan video dan film, sehingga siswa mendapatkan pengalaman belajar yang bermakna (Hamdunah et al., 2020; Ricu Sidiq, 2020). Karakteristik siswa dalam memahami dan menggali mteri berbedabeda terkadang ada siswa yang lebh cepat memahami materi begitu juga sebaliknya (Nurhamidah, 2018).

Selain itu, jika dilihat dari kualitas dan desain dari media, media e-comic berisi materi dan instruksi sederhana, komunikatif, dan bahasa yang jelas, sehingga mudah bagi siswa untuk memahami materi. Media pembelajaran e-comic berbasis problem-based learning materi siklus air pada setiap baru halaman yang dimulai dengan penutup, Kompetensi Dasar, indicator pembelajaran, tujuan pembelajaran, petunjuk, penjelasan materi hingga soal latihan. Daya tarik berupa huruf dan gambar bervariasi sesuai dengan karakteristik siswa sekolah dasar. Desain aplikasi pembelajaran mampu menarik perhatian siswa dan melibatkan siswa dalam belajar secara mandiri. Hal ini disebabkan aplikasi didesain secara menarik dan sederhana. Penyampaian materi tidak hanya menggunakan teks, tetapi juga menggunakan komponen-komponen multimedia seperti gambar, grafik, video, dan animasi. Multimedia menyediakan berbagai fitur untuk belajar secara kreatif (Shilpa, S. \& Sunita, 2016). Gaya tulisan, ukuran, spasi dan warna teks yang digunakan konsisten dan menarik. Keefektifan multimedia dapat menstimulasi perkembangan kognitif dan perkembangan bahasa anak, selain iti meningkatkan hasil belajar siswa (Widyatmojo, G., \& Muhtadi, 2017)

Temuan penelitian berkaitan e-comic berbasis problem based learning menghasilkan Science Comic berbasis problem based learning layak digunakan dalam pembelajaran dan dapat meningkatkan kemampuan berpikir siswa (Widiyatmoko, 2014). Media strip comic dengan model ADDIE dapat meningkatkan motivasi belajar siswa kelas V SD (Tegeh, 2018). Media komik digital layak dan siap diimplementasikan dengan sedikit revision pada aspek tertentu (Rohmanurmeta, 2019b). Selanjutnya media E-Comic dalam pembelajaran matematika lebih efektif dari pada menggunakan metode ceramah dalam pembelajaran (Siregar, 2019). Media pembelajaran E-Comic berbasis Problem Based Learning materi siklus air kelas V SD dapat membantu siswa memahami materi, dapat meningkatkan kemampuan berpikir kritis siswa dalam memecahkan permasalahan dalam pembelajaran. Selain itu, diharapkan media pembelajaran E-comic Berbasis Problem Solving ini dapat memotivasi siswa dalam mempelajari materi agar dapat memahami materi yang disampaikan dengan mudah. E-Comic berbasis Problem Based Learning materi siklus air kelas V SD yang dikembangkan dalam penilaiannya secara umum berkualitas sangat baik dan dapat meningkatkan keterampilan berpikir kritis dan hasil belajar peserta didik, namun dalam pengembangannya masih memiliki beberapa kelemahan. Kelemahan itu terdapat pada skala uji coba produk, hanya dilakukan dalam skala kecil yang melibatkan 1 (satu) sekolah. Uji 
coba produk ini juga hanya dilakukan pada kelas V SD Negeri 15 Dauh Puri. Selain itu, media e-comic berbasis problem-based learning tidak dilaksanakan sampai tahapan uji efektifitas.

\section{Simpulan}

Rancang bangun media pembelajaran E-Comic berbasis Problem Based Learning ini menggunakan model pengembangan ADDIE yang terdiri dari tahap Analisis (Analyze), Perancangan (Design), Pengembangan (Development), Implementasi (Implementation) pada tahap ini hanya dilaksanakan sampai uji coba perorangan, dan Evaluasi (Evaluation). Media pembelajaran E-Comic berbasis Problem Based Learning layak digunakan dalam pembelajaran. Berdasarkan hasil dari uji validitas tersebut dari ahli isi pembelajaran, ahli desain pembelajaran, ahli media pembelajaran dengan penilaian pada kategori sangat baik, dan uji coba perorangan yang memperoleh penilaian pada kualifikasi sangat baik. Hasil penelitian ini dapat dijadikan suatu referensi bagi penelitian lain dalam melakukan penelitian pengembangan yang sejenisnya, serta menindaklanjuti dengan uji efektifitas.

\section{Daftar Rujukan}

Aiman, U. \& R. A. R. A. (2020). Model Pembelajaran Berbasis Masalah (PBL) Terhadap Literasi Sains Siswa Kelas V Sekolah Dasar. Jurnal Pendidikan Dasar Flobamorata, 1(1), 105. https://doi.org/10.51494/jpdf.v1i1.195.

Aprilla. (2020). Pengembangan Media Pembelajaran Matematika Berbasis Komik Untuk Meningkatkan Keterampilan Pemecahan Masalah Siswa. Thinking Skills and Creativity Journal, 3(2).

Astuti, Y., \& Setiawan, B. (2013). Pengembangan lembar kerja siswa (LKS) berbasis pendeka-tan inkuiri terbimbing dalam pembelajaran kooperatif pada materi kalor. Jurnal Pendidikan IPA Indonesia, 2(1), 88-92. https://doi.org/10.15294/jpii.v2i1.2515.

Dewi, K., Sadia, I. W., \& Ristiati, N. P. (2013). Pengembangan Perangkat Pembelajaran IPA Terpadu Dengan Setting Inkuiri Terbimbing Untuk Meningkatkan Pemahaman Konsep Dan Kinerja Ilmiah Siswa. E-Journal Program Pascasarjana Universitas Pendidikan Ganesha, 3(1), 1-11. https://ejournalpasca.undiksha.ac.id/index.php/jurnal_ipa/article/view/548/340.

Drs. Ida Bagus Surya Manuaba, S. (2017). Pengaruh Model Problem Based Learning Berbantuan Media Audio Visual Terhadap Penguasaan Kompetensi Ips. MIMBAR PGSD Undiksha, 5(2), 1-8. https://doi.org/10.23887/jjpgsd.v5i2.11000.

Hamdunah, Juftri, L. H., \& Handayani, S. (2020). Pelatihan Pengembangan Bahan Ajar Berbasis Masalah. , 1(2), 98-105. https://doi.org/. Community Engagement and Emergence Journal (CEEJ), 1(2), 98-105. https://doi.org/10.37385/ceej.v1i2.115.

Indriasih, A., Sumaji, Badjuri, \& Santoso. (2020a). Pengembangan E-Comic Sebagai Media Pembelajaran Untuk Meningkatkan Kecakapan Hidup Anak Usia Dini. Jurnal Ilmiah Kependidikan, 10(2), 154-166. https://doi.org/10.17509/jpm.v3i9459.

Indriasih, A., Sumaji, S., Badjuri, B., \& Santoso, S. (2020b). Pengembangan E-Comic Sebagai Media Pembelajaran Untuk Meningkatkan Kecakapan Hidup Anak Usia Dini. Refleksi Edukatika: Jurnal Ilmiah Kependidikan, 10(2), 154-162. https://doi.org/10.24176/re.v10i2.4228.

Januarisman, E., \& Ghufron, A. (2016). Pengembangan Media Pembelajaran Berbasis Web Mata Pelajaran Ilmu Pengetahuan Alam Untuk Siswa Kelas VII. Jurnal Inovasi Teknologi Pendidikan, 3(2), 166. https://doi.org/10.21831/jitp.v3i2.8019.

Lailiyah. (2020). Pengembangan Media Komik Siklus Air Untuk Meningkatkan Hasil Belajar Siswa Kelas V Di Sekolah Dasar. Jurnal Pendidikan Guru Sekolah Dasar, 8(1), 1-11. 
https://jurnalmahasiswa.unesa.ac.id/index.php/jurnal-penelitian-

pgsd/article/view/33521/29990.

Mahuze, P. N. (2017). Peranan Media Gambar Dalam Proses Pembelajaran Agama Katolik. $\begin{array}{llll}\text { Jurnal Masalah } & \text { Pastoral, } & \text { 5(1), }\end{array}$ https://ojs.stkyakobus.ac.id/index.php/JUMPA/article/view/36.

Musafanah, H. J. S. \& Q. (2017). Pengembangan Media Koran Melalui Flipbook Berupa EBOOK Pada Materi IPA. Elementary School, 4(2), 205-211. https://doi.org/10.31316/esjurnal.v4i2.179.

Nurhamidah.I. (2018). Problematika Kompetensi Pedagogi Guru Karakteristik Peserta Didik. Jurnal Teori Dan Praksis Pembelajaran IPS, 3(1). https://doi.org/10.17977/um022v3i12018p027.

Nurhasanah, I. A., Sujana, A., \& Sudin, A. (2016). Penerapan Metode Role Playing Untuk Meningkatkan Hasil Belajar Siswa Pada Materi Hubungan Mahluk Hidup Dengan Lingkungannya. Jurnal Pena Ilmiah, 1(1), 611-620. https://ejournal.upi.edu/index.php/penailmiah/article/download/2992/2059.

Pratama, M. R. F., Mulyani, E., \& Suratno, S. (2019). Molecular Docking Study of Akar Kuning (Arcangelisia flava) Secondary Metabolites as Src Inhibitor. Indonesian $\begin{array}{llll}\text { Journal of Cancer } & \text { Chemoprevention, }\end{array}$ https://doi.org/10.14499/indonesianjcanchemoprev 10iss3pp122-130.

Pratiwi. (2017). Pengembangan Buku Cerita Anak Dengan Menginsersi Budaya Lokal Dalam Tema Kegemaranku Untuk Kelas I Sekolah Dasar. Jurnal Ilmiah Pendidikan Dan Pembelajaran, 1(03).

Purnomo, H., \& Wilujeng, I. (2016). Pengembangan Bahan Ajar dan Instrumen Penilaian IPA Tema Indahnya Negeriku Penyempurnaan Buku Guru dan Siswa Kurikulum 2013. Jurnal Prima Edukasia, 4(1), 67. https://doi.org/10.21831/jpe.v4i1.7697.

Putri, W. N. (2017). Pengaruh Media Pembelajaran Terhadap Motivasi Belajar Bahasa Arab Siswa Madrasah Tsanawiyah. LISANIA: Journal of Arabic Education and Literature, 1(1), 1-16. https://doi.org/10.18326/lisania.v1i1.1160.

Ricu Sidiq, \& N. (2020). Pengembangan E-Modul Interaktif Berbasis Android pada Mata Kuliah Strategi Belajar Mengajar. Jurnal Pendidikan Sejarah, 9(1), 1-14. https://doi.org/10.21009/JPS.091.01.

Rivai, A. (2021). Pengaruh Pengawasan, Disiplin dan Motivasi Terhadap Kinerja Guru. Maneggio: Jurnal Ilmiah Magister Manajemen, 4(1), 11-22. http://jurnal.umsu.ac.id/index.php/MANEGGIO/article/view/6715.

Rohmanurmeta, M. . \& D. . (2019a). Pengembangan Komik Digital Pelestarian Lingkungan Berbasis Nilai Karakter Religi Untuk Pembelajaran Tematik pada Siswa Sekolah Dasar. Studi Kependidikan Dan Keislaman, 9(2). https://doi.org/10.24269/muaddub.v11i2.1213.

Rohmanurmeta, M. . \& D. . (2019b). Pengembangan Komik Digital Pelestarian Lingkungan Berbasis Nilai Karakter Religi Untuk Pembelajaran Tematik pada Siswa Sekolah Dasar https://doi.org/10.2. MUADDIB: Studi Kependidikan Dan Keislaman, 9(02), 131-141. https://doi.org/10.24269/muaddub.v11i2.1213.

Rostikawati, D. A., \& Permanasari, A. (2016). Rekonstruksi Bahan Ajar dengan Konteks Socio-Scientific Issues pada Materi Zat Aditif Makanan untuk Meningkatkan Literasi Sains Siswa Reconstruction of Learning Materials with Socio-Scientific Issues Context on Food Additives Content to Improving Student. Jurnal Inovasi Pendidikan IPA, 2(2), 156-164. https://journal.uny.ac.id/index.php/jipi/article/view/8814/9018.

Rubini, B., Permanasari, A., \& Yuningsih, W. (2018). Learning Multimedia Based on Science Literacy on the Lightning Theme. Journal of Science Learning and Research, 4(2), 89-104. https://doi.org/10.30870/jppi.v4i2.3926. 
Saripudin, E., Sari, IJ, \& Mukhtar, M. (2018). Using Macro Flash Animation Media on Motion Material to Improve Learning Achievement for Learning Science in Junior High School. , 4 (1),. Journal of Science Research and Learning, 4(1), 68-75. https://doi.org/10.30870/jppi.v4i1.3316.

Shilpa, S. \& Sunita, M. (2016). A study an interactive elementary education (3-6) with multimedia. International Journal of Home Science, 2(1), 214-215.

Siregar, N. dkk. (2019). Pengembangan Media Pembelajaran E-Comic dalam Pembelajaran Matematika. Journal of Mathematics Education and Science, 2(1). https://doi.org/10.32665/james.v2i1.47.

Tegeh, I. M. (2014). Model Penelitian Pengembangan. Graha Ilmu.

Tegeh, I. M. (2018). Pengembangan Media Strip Comic Dengan Model Addie Pada Mata Pelajaran IPA Untuk Meningkatkan Motivasi Belajar Siswa Kelas V Di SD Negeri 1 Sari Mekar. Jurnal Edutech Undiksha, 6(2), 245-255.

Utami, D. (2019). Model Problem Based Learning (Pbl) Berbantuan Mediaaudio Visual Untuk Meningkatkan Keterampilan Berpikir Kritis Pada Siswa Kelas 5 Sekolah Dasar. MAJU, 6(1). https://doi.org/10.24903/pm.v5i1.461.

Wahyugi, R., \& Fatmariza, F. (2021). Engembangan Multimedia Interaktif Menggunakan Software Macromedia Flash 8 Sebagai Upaya Meningkatkan Motivasi Belajar Siswa Sekolah Dasar. Edukatif: Jurnal Ilmu Pendidikan, 3(3), 791-800. https://www.edukatif.org/index.php/edukatif/article/view/439/pdf.

Widiana, I. W. (2016). Pengembangan Asesmen Proyek Dalam Pembelajaran Ipa Di Sekolah Dasar. JPI (Jurnal Pendidikan Indonesia), 5(2), 147. https://doi.org/10.23887/jpiundiksha.v5i2.8154.

Widiyatmoko, F. dan. (2014). Pengembangan Science Comic Berbasis Problem Based Learning sebagai Media Pembelajaran pada Tema Bunyi dan Pendengeran untuk Siswa SMP. Jurnal Pendidikan IPA Indonesia, 3(2). https://doi.org/10/15294/jpii.v3i2 .3114 .

Widyatmojo, G., \& Muhtadi, A. (2017). Pengembangan Multimedia Pembelajaran Interaktif Berbentuk Game untuk Menstimulasi Aspek Kognitif dan Bahasa Anak TK. Jurnal Inovasi Teknologi Pendidikan, 4(1), 38-49.

Zainudin, \& Wijayanti, R. (2021). Pengembangan perangkat pembelajaran fisika pada masa pandemi covid-19 berbasis keterampilan berpikir. Jurnal Ilmiah Pendidikan IPA, $3(1)$, 43-49. http://jurnal.stkippgritulungagung.ac.id/index.php/eduproxima\%0APENGEMBANG AN. 